\title{
Refractoriness about adaptation
}

\author{
Robert P. O'Shea ${ }^{1,2 *}$ \\ 1 Discipline of Psychology, School of Health and Human Sciences, Southern Cross University, Coffs Harbour, NSW, Australia \\ 2 BioCog, Institute of Psychology, University of Leipzig, Leipzig, Germany \\ *Correspondence: robert.oshea@scu.edu.au
}

Edited by:

Mark E. McCourt, North Dakota State University, USA

Reviewed by:

John J. Foxe, Albert Einstein College of Medicine, USA

Keywords: EEG, ERP, neural adaptation, neural fatigue, predictive coding, repetition suppression, stimulus specific adaptation, visual mismatch negativity (vMMN)

\section{A commentary on}

Visual mismatch negativity: a predictive coding view

by Stefanics, G., Kremláček, J., and Czigler, I. (2014). Front. Hum. Neurosci. 8:666, 1-19. doi: 10.3389/fnhum.2014.00666

"Let us go down, and there confound their language, that they may not understand one another's speech."

Genesis 11:7 (King James Version, 1611).

Recently Stefanics et al. (2014) reviewed the visual (v) mismatch negativity $(\mathrm{MMN})$, a negative shift in voltage of an event-related potential (ERP) to an unpredictable, rare, deviant stimulus in a regular sequence of identical, standard stimuli. Stefanics et al. have written a wonderfully comprehensive review of the vMMN, concluding that it might be a sign of predictive coding (Mumford, 1992; Friston, 2005; Winkler and Czigler, 2012).

I have two comments:

1. Stefanics et al. referred to one explanation of the MMN, needing to be distinguished from true predictive coding, as "refractoriness." I argue that a better term for refractoriness is "adaptation."

2. Stefanics et al. (2014) said the MMN debate about adaptation, as defined above, was "not particularly productive" (p. 2), although they did concede that it needs to be taken into account. I argue that adaptation ought to be harmonized into any complete MMN explanation.
I should emphasize that I have no quibble with the logical necessity of distinguishing sluggishness of repeatedly stimulated neurons from the MMN and that this has been achieved numerous times, as Stefanics et al. have recorded.

\section{ETYMOLOGY AND MEANING OF REFRACTORINESS AND ADAPTATION}

By "refractoriness," Stefanics et al. meant a "neurophysiological effect reflecting neuronal 'fatigue"' (p. 3) or "synaptic depression due to the depletion of vesicles from the presynaptic terminal" (p. 9). They gave other names for the "response attenuation ... (from repeated presentations of a standard, including) repetition suppression, stimulus-specific adaptation (SSA), [and] habituation" (p. 3), although these are not strictly synonyms.

O'Shea (2015) showed that "refractoriness" is common in the MMN (and ERP) literature but rare in related literatures.

Refractoriness comes from Latin refractarius: stubborn or obstinate-its meaning in ordinary language - and is different from its MMN meaning-tired. The physiological meaning of the adjective "refractory" refers to the state of a neuron or cardiac nerve after electrical activity begins for which it is impossible to generate more, no matter how intense the stimulation (the absolute refractory period) or for which it very difficult to generate more (the relative refractory period) (e.g., Hodgkin, 1948; Chapman, 1966). For neurons, these refractory periods are of the order of milliseconds-much too short to be responsible for the refractoriness supposed to underlie the MMN. Moreover, synaptic depletion occurs only at stimulation rates much higher than typically used in vMMN studies, over $10 \mathrm{~Hz}$ (FernándezAlfonso and Ryan, 2004).

There is also a general slowing of responses, such as key presses, when people are given a task to perform shortly after another-the psychological refractory period (Welford, 1952), But this is not from fatigue of neurons, but likely from a central bottleneck and serial preparation of responses (Pashler, 1994).

Adaptation comes from Latin adaptare: to fit. In ordinary language it means to make something suitable for a new purpose. In cognitive neuroscience, it means a change in the responsiveness of neurons to fit them to the range of current inputs (Webster, 2012). Adaptation is not a defect of neurons but something that has been designed by evolution to ensure survival. It likely involves some active process, because some neurons of sensory pathways do not adapt (Ohzawa et al., 1985; Solomon et al., 2004).

\section{ADAPTATION AND THE MMN}

One view of predictive coding is that it is an epistemic approach aimed at why cognitive-neuroscience phenomena occur, sitting comfortably with approaches that are aimed at mechanistic explanations-at how such phenomena occur (such as via adaptation) (Garrido et al., 2008, 2009). To restrict understanding of adaptation to neural fatigue or to see adaptation as opposed to the MMN could limit the richness of understanding that viewing phenomena from two perspectives can yield.

The predictive-coding explanation is that the brain constructs predictions of future sensory input from past sensory input and matches these against actual input, generating an error signal when the 
input is different from the prediction. This occurs at different levels of the brain, each one involving more and more abstract properties of sensory input.

This is rather similar to the epistemic role of adaptation: to alter the responsiveness of neurons based on past input to ensure they are maximally responsive to the range of inputs. It occurs at different levels of the brain, each one involving more and more abstract properties of sensory input. For example, in the visual system, cones adapt to the prevailing light level to operate over more than three orders of magnitude of light intensity (Valeton and Van Norren, 1983). Retinal ganglion cells encode contrast and they show contrast adaptation, allowing for meaningful signals whatever the range of contrasts in the visual field (Solomon et al., 2004). They also adapt to more complex properties of the visual scene, such as orientation and spatiotemporal modulations (Hosoya et al., 2005). Cortical neurons adapt to the properties they encode, such as orientation, spatial frequency, and motion (Clifford et al., 2007). Inferotemporal cortical neurons adapt functionally to the shapes of stimuli presented anywhere in their receptive fields (De Baene and Vogels, 2010).

Studies suggesting that adaptation needs to be harmonized with MMN explanations include:

- An extensive theoretical treatment (May and Tiitinen, 2010).

- Unpredictablity's reducing adaptation (Summerfield et al., 2008; Kok et al., 2014).

- Stefanics et al's conclusion that stimulus-specific adaptation (Nelken and Ulanovsky, 2007) is a possible neural substrate for MMN.

- Musall et al.'s (2014) study showing that mechanical stimulation of rats' whiskers resulted in the rats' being behaviorally more sensitive to a deviant stimulus than when they stimulated the rats' cortices optogenetically and perceptually identically, bypassing cortical and downstream adaptation.

\section{CONCLUSION}

Using "refractoriness," a term that is essentially unknown in fields such as fMRI, animal models, and psychophysics, creates a Tower of Babel. I believe it is better in science if one's language unites, rather than divides. Replacing "refractoriness" in the MMN vocabulary with adaptation terms and searching for a rapprochement between adaptation and MMN could bring considerable explanatory benefits.

\section{ACKNOWLEDGMENTS}

In writing this paper, I conferred with various experts in ERPs, MMN, and adaptation. They all know much more about these topics than I do and treated the concerns and drafts of a newcomer with charity, tolerance, good humor, helpfulness, support, and encouragement. I am grateful to all of them including Colin Clifford, István Czigler, Sabine Grimm, Jan Kremláček, Bradley Jack, Dagmar Müller, Erich Schröger, Walter Ritter, Urte Roeber, Florian Scharf, Gábor Stefanics, Alessandro Tavano, Andreas Widmann, and Nicole Wetzel.

\section{REFERENCES}

Chapman, R. A. (1966). The repetitive responses of isolated axons from the crab, Carcinus maenas. J. Exp. Biol. 45, 475-488.

Clifford, C. W., Webster, M. A., Stanley, G. B., Stocker, A. A., Kohn, A., Sharpee, T. O., et al. (2007). Visual adaptation: Neural, psychological and computational aspects. Vision Res. 47, 3125-3131. doi: 10.1016/j.visres.2007.08.023

De Baene, W., and Vogels, R. (2010). Effects of adaptation on the stimulus selectivity of macaque inferior temporal spiking activity and local field potentials. Cereb. Cortex 20, 2145-2165. doi: 10.1093/cercor/bhp 277

Fernández-Alfonso, T., and Ryan, T. A. (2004). The kinetics of synaptic vesicle pool depletion at CNS synaptic terminals. Neuron 41, 943-953. doi: 10.1016/S0896-6273(04) 00113-8

Friston, K. (2005). A theory of cortical responses. Philos. Trans. R. Soc. Lond. B Biol. Sci. 360, 815-836. doi: 10.1098/rstb.2005.1622

Garrido, M. I., Friston, K. J., Kiebel, S. J., Stephan, K. E., Baldeweg, T., and Kilner, J. M. (2008). The functional anatomy of the MMN: a DCM study of the roving paradigm. Neuroimage 42, 936-944. doi: 10.1016/j.neuroimage.2008. 05.018

Garrido, M. I., Kilner, J. M., Stephan, K. E., and Friston, K. J. (2009). The mismatch negativity: a review of underlying mechanisms. Clin. Neurophysiol. 120, 453-463. doi: 10.1016/j.clinph. 2008.11.029

Hodgkin, A. L. (1948). The local electric changes associated with repetitive action in a non-medullated axon. J. Physiol. 107, 165-181.

Hosoya, T., Baccus, S. A., and Meister, M. (2005). Dynamic predictive coding by the retina. Nature 436, 71-77. doi: 10.1038/nature 03689
King James Version. (1611). The Holy Bible. London: Robert Barker, Printer to the Kings Most Excellent Maiestie.

Kok, P., Failing, M. F., and De Lange, F. P. (2014) Prior expectations evoke stimulus templates in the primary visual cortex. J. Cogn. Neurosci. 26, 1546-1554. doi: 10.1162/jocn_a_00562

May, P. J. C., and Tiitinen, H. (2010). Mismatch negativity (MMN), the deviance-elicited auditory deflection, explained. Psychophysiology 47, 66-122. doi: 10.1111/j.1469-8986.2009. 00856.x

Mumford, D. (1992). On the computational architecture of the neocortex. II. The role of corticocortical loops. Biol. Cybern. 66, 241-251. doi: 10.1007/BF00202389

Musall, S., Von Der Behrens, W., Mayrhofer, J. M., Weber, B., Helmchen, F., and Haiss, F. (2014). Tactile frequency discrimination is enhanced by circumventing neocortical adaptation. Nat. Neurosci. 17, 1567-1573. doi: 10.1038/ nn. 3821

Nelken, I., and Ulanovsky, N. (2007). Mismatch negativity and stimulus-specific adaptation in animal models. J. Psychophysiol. 21, 214-223. doi: 10.1027/0269-8803.21.34.214

O'Shea, R. P. (2015). Searching for Refractoriness. Available online at: http://robertposhea.blogspot. com/2015/01/searching-for-refractoriness.html (Accessed January 11, 2015).

Ohzawa, I., Sclar, G., and Freeman, R. D. (1985). Contrast gain control in the cat's visual system. J. Neurophysiol. 54, 651-667.

Pashler, H. (1994). Dual-task interference in simple tasks: data and theory. Psychol. Bull. 116, 220-244. doi: 10.1037/0033-2909.116.2.220

Solomon, S. G., Peirce, J. W., Dhruv, N. T., and Lennie, P. (2004). Profound contrast adaptation early in the visual pathway. Neuron 42 , 155-162. doi: 10.1016/S0896-6273(04) 00178-3

Stefanics, G., Kremláček, J., and Czigler, I. (2014). Visual mismatch negativity: a predictive coding view. Front. Hum. Neurosci. 8:666, 1-19. doi: 10.3389/fnhum.2014.00666

Summerfield, C., Trittschuh, E. H., Monti, J. M., Mesulam, M. M., and Egner, T. (2008). Neural repetition suppression reflects fulfilled perceptual expectations. Nat. Neurosci. 11, 1004-1006. doi: 10.1038/nn.2163

Valeton, J. M., and Van Norren, D. (1983). Light adaptation of primate cones: an analysis based on extracellular data. Vision Res. 23, 1539-1547. doi: 10.1016/0042-6989(83)90167-0

Webster, M. A. (2012). Evolving concepts of sensory adaptation. F1000 Biol. Rep. 4, 1-21. doi: 10.3410/B4-21

Welford, A. T. (1952). The "psychological refractory period" and the timing of high-speed performance: a review and a theory. $\mathrm{Br}$. J. Psychol. 43, 2-19. doi: 10.1111/j.2044-8295.1952. tb00322.x

Winkler, I., and Czigler, I. (2012). Evidence from auditory and visual event-related potential (ERP) studies of deviance detection (MMN and vMMN) linking predictive coding theories and perceptual object representations. Int. J. Psychophysiol. 83, 132-143. doi: 10.1016/j.ijpsycho. 2011.10.00 
Conflict of Interest Statement: The author declares that the research was conducted in the absence of any commercial or financial relationships that could be construed as a potential conflict of interest.

Received: 13 January 2015; accepted: 14 January 2015; published online: 04 February 2015.
Citation: O'Shea RP (2015) Refractoriness about adaptation. Front. Hum. Neurosci. 9:38. doi: 10.3389/ fnhum.2015.00038

This article was submitted to the journal Frontiers in Human Neuroscience.

Copyright (c) 2015 O'Shea. This is an open-access article distributed under the terms of the Creative Commons
Attribution License (CC BY). The use, distribution or reproduction in other forums is permitted, provided the original author(s) or licensor are credited and that the original publication in this journal is cited, in accordance with accepted academic practice. No use, distribution or reproduction is permitted which does not comply with these terms. 